\title{
Relationship between Leisure Facilitators and Serious Leisure among Female Korean College Soccer Participants
}

\author{
Hee Yeob Kang ${ }^{1}$, Hyung Hoon Kim ${ }^{2}$, Hyun Wook Choi ${ }^{1}$, Won Il Lee ${ }^{3} \&$ Chul Won Lee ${ }^{1}$ \\ ${ }^{1}$ Department of Sport Industry Studies, Yonsei University, Seoul, Republic of Korea \\ ${ }^{2}$ Department of Taekwondo \& Security, Honam University, Gwangju, Republic of Korea \\ ${ }^{3}$ The Graduate School of Education, Yongin University, Yongin, Republic of Korea \\ Correspondence: Chul Won Lee, Department of Sport Industry Studies, Yonsei University, Seoul, Republic of \\ Korea. Tel: 82-2-2123-3186. E-mail: wakeford@yonsei.ac.kr
}

Received: February 2, 2017

doi:10.5539/ass.v13n4p117
Accepted: February 13, 2017 Online Published: March 24, 2017

URL: https://doi.org/10.5539/ass.v13n4p117

\begin{abstract}
This study identifies the relationship between leisure facilitators and serious leisure of female college soccer participants. To this end, data were collected from a total of 223 surveys from participants in female college soccer participants. The collected data were analyzed and interpreted using SPSS and AMOS program. Frequency analysis, confirmatory factor analysis, reliability analysis, correlation analysis and multiple regression analysis were performed. All tests were performed using a .05 significance level. The results of this study were as follows. First, intrapersonal facilitators of leisure facilitators had a positive effect on serious leisure. Second, interpersonal facilitators of leisure facilitators had a positive effect on serious leisure. Third, structural facilitators of leisure facilitators had a positive effect on serious leisure.
\end{abstract}

Keywords: leisure facilitators, serious leisure, female college soccer

\section{Introduction}

\subsection{Introduction}

Participation in sports during leisure time has gradually increased in Korean society. According to a survey on citizens' sports participation (September 9, 2015), the rate of participation in sports activities once a week or more was steadily increasing from $39.90 \%$ participated in 1989 to $42.4 \%$ in 2008 than $45.5 \%$ in 2013 . As of 2010, these figures were similar to those from the Netherlands (56\%) and France $(50 \%)$ where life sports were a well-developed part life (The Ministry of Culture, Sports and Tourism, 2015).

As mentioned above, the popularity of sports participation in during leisure time shows a tendency to extend throughout all social groups in Korea. In particular, the participation of female college students in sports is noticeably rising. The relevant reasons are an increase in the attention paid toward health, the establishment of sports-friendly environments for female college students, and the growth of social support for female college students.

Adult participation in sports has psychological, physical, and social benefits. The advantages of physical leisure activities can motivate adults to engage in physical activities during leisure time. In particular, the participation of female adults in sports requires the overcoming of a variety of leisure constraints (Crawford, Jackson, \& Godbey, 1991; Hubbard \& Mannel, 2001; Jackson, 1993; Jackson, Crawford, \& Godbey, 1993; Kim, Heo, Chun, \& Lee, 2011). To overcome such constraints, a stimulus or motive for leisure activity is important. To encourage female college students to seriously participate in leisure activities, factors that promote such leisure activities should exist (Dilley \& Scraton, 2010; Stebbins, 2001).

Considering that some people actively participate in leisure activities despite of individual leisure constraints and that others have negative attitudes toward leisure activities even in the absence of individual leisure constraints, we cannot assume that simply the existence of leisure constraints determines engagement in leisure activities. Sometimes, individuals with various constraints restricting their participation in sports activities, such as those who have experienced physical injuries or traumas, continue to engage in sports due to the influences of leisure (Calhoun \& Tedeschi, 1999; Stains, Schnider, Chavez, \& Shinew, 2009). Chun and Lee (2008) state that leisure 
participation can provide unique competence development, meaningful relationship construction, personal implication formation, and positive emotional development for individuals with spinal cord injuries with under the psychological limitations; these unique acvantages can act as significant motives for leisure activities. Thus, in addition to constraints, a variety of psychological factors should be considered in leisure participation.

In this regard, Raymore (2002) suggests a theory of leisure facilitators to understand leisure constraints as well as participation in leisure activities. Leisure constraints negotiation and leisure facilitators function simultaneously in the case of participation and non-participation in leisure activities. By supplementing the existing theory of leisure constraints, which states that the alleviation of leisure constraints can lead to participation in leisure activities, the theory of leisure facilitators presents the concept of factors that enhance leisure participation.

Therefore, this study analyzes the factors of facilitators and their relations to serious leisure participation, targeting female college students who play soccer during their leisure time, and suggests the significance of leisure facilitator as an impetus that leads female college students to be immersed in soccer.

\subsection{Leisure Facilitators and Serious Leisure}

Leisure facilitators is classified as intrapersonal, interpersonal, and structural facilitator based on the structure of the leisure constraint, a major factor in the determination of individual leisure activity participation positively affecting the participation (Raymore, 2002). Previous studies have found that leisure facilitator induce continual leisure activities and positively influence recreation specialization and flow experiences (Korotkov, McLean, \& Hamilton, 2011; Sa, Lee, Kim, Chun, \& Nam, 2015; Lewis, Patterson, \& Pegg, 2013).

Raymore (2002) defines leisure facilitators as a factor that forms a leisure preference or increases leisure activity participation. In previous studies, leisure facilitators have been proposed as a crucial factor for attracting constant leisure activities and positively impacting serious leisure (Lawton, 1994; Sa et al., 2015). Lawton (1994) states that passionate individuals are likely to be immersed in leisure activities and their personal characteristics promote their engagement in leisure activity. Sa et al. (2015) identify recreation professionalization to improve the levels of leisure facilitator perceived by women participating in running events.

Recently, the participation of female college students in sports activities has increased in Korea. Female students are experiencing new sports games through student groups. The number of those who are engage in soccer has increased greatly; female students are, participating actively in soccer activities based on professional skill and knowledge (Jo, 2011). This phenomenon is exemplified by the increase in female college students participating in soccer competitions. Thus, female college students participating in soccer competitions can be regarded to be engaged in soccer activities as serious leisure, beyond everyday leisure (Lewis et al., 2013; Mackellar, 2009; Siegenthaler \& O'Dell, 2003; Stebbins, 1992; Stebbins, 2001). Stebbins' (1982) serious leisure was first applied to identify leisure participant's behavior and characteristics in leisure study sector. Serious leisure are show from armature, hobbyist, and volunteer which defined as obtaining professional skill and knowledge pursuing professionalism. The characteristics of serious leisure are persevere, career, personal effort, durable benefit, strong identity, and unique ethos. We could possibly assume that female college soccer participants are participating soccer as serious leisure since they gained technical skills and knowledge as well as professionalism during the soccer tournament (Stebbins, 1992).

Therefore, factor of the leisure facilitator must be analyzed in terms of female college students engaged in continued soccer activities. In the field of leisure studies, there have not been sufficient studies to examine the relationships between leisure facilitator and serious leisure. To explore the engagement in leisure activity, in-depth studies on leisure facilitator factors as well as leisure constraints factors should be conducted. In this context, this study tries to investigate the empirical relations between leisure facilitator and serious leisure, targeting female college students engaged in soccer activities through college student groups. Because the purpose of this study is to identify the relationships between leisure facilitator and serious leisure among female college students soccer participants, our hypothesis was set as follows.

Hypothesis 1. Intrapersonal facilitator has a positive effect serious leisure.

Hypothesis 2. Intrerpersonal facilitator has a positive effect on serious leisure.

Hypothesis 3. Structural facilitator has a positive effect on serious leisure.

\section{Method}

\subsection{Participants and Procedure}

The women sampled in this study were chosen from among female college students who participated in soccer in 
college sport club. Data were collected during a women's soccer tournament on May 9, 2015. The researcher visited female college soccer tournament and done questionnaires. Questionnaires are distributed and gathered from the participants after the explanation about the purpose of the study. The researcher requested the participants to fill in the survey on voluntary basis and the participants completed the survey for approximately 10 minutes. Completed surveys were immediately collected. A total of 240 questionnaires were distributed to the tournament participants. A self-administration method was used to fill out the questionnaires. Finally, 240 questionnaires were collected and, after the removal of incomplete surveys, 223 questionnaires were used for data analysis. A summary of the general characteristics of the study is shown in Table 1.

Table 1. Demographic characteristics of participants

\begin{tabular}{|c|c|c|c|}
\hline & classification & $\mathrm{N}$ & $\%$ \\
\hline \multirow{4}{*}{ Year } & Freshman & 64 & 28.7 \\
\hline & Sophomore & 58 & 26.0 \\
\hline & Junior & 60 & 26.9 \\
\hline & Senior & 41 & 18.4 \\
\hline \multirow{4}{*}{ Frequency of leisure activity } & 1 day & 50 & 22.4 \\
\hline & 2 days & 120 & 53.8 \\
\hline & 3 days & 34 & 15.2 \\
\hline & 4 days or more & 19 & 8.5 \\
\hline \multirow{5}{*}{ Duration of leisure activity } & Under 1 years & 74 & 33.2 \\
\hline & $1-2$ years & 57 & 25.6 \\
\hline & $2-3$ years & 38 & 17.0 \\
\hline & $3-4$ years & 25 & 11.2 \\
\hline & 4 years or more & 29 & 13.0 \\
\hline \multirow{3}{*}{ Daily leisure activity time } & Under 2 hours & 72 & 32.2 \\
\hline & $2-3$ hours & 117 & 52.5 \\
\hline & 3 hour or more & 34 & 15.2 \\
\hline
\end{tabular}

\subsection{Measurements}

The questionnaire method was the research method used in this study. This method was used to examine the relationship between leisure facilitators and serious leisure among women's soccer participants.

First, to analyze the basic demographic characteristics, a questionnaire was disseminated that examined four factors: college year, participation frequency, participation duration, and daily leisur activity time. Since the study aimed female college student, grade included to the general characteristics than age.

Second, Leisure facilitators was measured using a questionnaire used by Song and Lee (2006) for a leisure facilitator analysis of a five-day school system for the youth. This questionnaire, consisting of three factors of 11 items, was used in this study. Leisure facilitator scale was taken from Raymore (2002) and was modified by Song and Lee (2006) to fit the study. The sub- factors of leisure facilitator include intrapersonal facilitator (three questions), interpersonal facilitator (three questions), and structural facilitator (five questions).

Third, the serious leisure scale was first developed by Stebbins (1992) and was modified by Tsaur \& Liang (2008); its six factors in 18 questions are: persevere, career, personal effort, durable benefit and rewards, strong identify, and unique ethos. The value was calculated by using mean value of each factor. Questionnaires were measured on a five-point Likert scale ranging from "Strongly disagree" (1) to "Strongly agree" (5).

\subsection{Data Analysis}

The complete data were analyzed after coding, using the programs SPSS and AMOS for Windows. The procedure for data analysis is as follows.

To define demographic information for the respondents to the questionnaire, a frequency analysis was conducted. To test the reliability of the scales, Cronbach's a coefficient, which is a measure of internal consistency between questions, was calculated. All alpha coefficients were above the cut-off point of 0.7 , indicating an acceptable level of reliability for each construct (Nunnally, 1978). To test construct validity, confirmatory factor analysis was conducted. Confirmatory factor analysis was conducted rather than exploratory factor analysis in this study because scales used in this study have been verificated for construct validity in previous studies (Kline, 2015). 
For sufficient level of convergent validity for the measurement model, All AVE and CR values for the multi-item scales must appear greater than the minimum criteria of 0.5 and 0.7, respectively (Hair, Black, Babin, Anderson, \& Tatham, 2006). For sufficient level of discriminant validity, the AVE of each construct must appear greater than the squared correlation coefficients for corresponding inter-constructs (Fornell \& Larcker, 1981). Serious leisure scale combined to single measure variable through item parceling after construct validity verification. The study followed previous research (Chen, 2014) on combining single measure variable of 6 sub-factor of serious leisure, and based on that the study analyzied single factor from 6 sub-factor through unidimensionality item parceling. Correlation analysis was conducted on each factor to confirm the correlation coefficients and to test the multicollinearity. Multicollinearity must be tested as it is general problem. Two independent variables having a correlation coefficient of 0.7 or higher may weaken the results of the analysis (Tabachnick \& Fidell, 2001). The relationship between leisure facilitators and serious leisure was analyzed through multiple regression analysis.

\section{Results}

\subsection{Validity and Reliability Test}

Before the regression analysis was conducted, the reliability and construct validity of the scale used in this study were tested. Reliability analysis was conducted by using Cronbach's $\alpha$ coefficient. The value of Cronbach's $\alpha$ was from 0.714 to 0.880 , which supports the clear internal consistency of the measurement instrument. Confirmatory factor analysis was conducted to test the construct validity of the scale. The measurement model derived from the CFA showed satisfactory levels of on all goodness-of-fit. Convergent and discriminant validity were performed to verify construct validity. To verify convergent validity, all average variance extracted (AVE) and composite reliability (CR) values for the multi-item scales were utilized. Accordingly, CR and AVE were calculated for every factor to test convergent validity. All AVE and CR values for the multi-item scales were greater than the minimum criteria of 0.5 and 0.7 , indicating a sufficient level of convergent validity for the measurement model. To verify the discriminant validity of the constructs, the most conservative method, using AVE, confirmed that the discriminant, as the highest squared correlation between intrapersonal leisure facilitators and durable benefit (.363), was smaller than the AVE for corresponding inter-constructs(.560 - .759). This result confirms that there was a sufficient level of discriminant validity in the measurement model. The results of reliability and construct validity are shown in Table 2 and 3.

Table 2. Model fit of measurement model

\begin{tabular}{cccccc}
\hline & $\chi^{2}$ & $d f$ & TLI & CFI & RMSEA \\
\hline Leisure facilitators & 86.19 & 39 & 0.925 & 0.947 & 0.074 \\
Serious leisure & 258.04 & 136 & 0.923 & 0.939 & 0.064 \\
\hline
\end{tabular}

Table 3. Results of CFA for the Measurement Model

\begin{tabular}{|c|c|c|c|c|}
\hline Item & Factor loading & $\mathrm{CR}$ & AVE & $\alpha$ \\
\hline \multicolumn{5}{|l|}{ Serious Leisure } \\
\hline Even if I am busy, I take part in soccer & .648 & \multirow{3}{*}{.845} & \multirow{3}{*}{.647} & \multirow{3}{*}{.767} \\
\hline Even if I am tired, I take part in soccer & .825 & & & \\
\hline Even if skill doesn’t improve, I keep trying & .648 & & & \\
\hline I have special knowledge on soccer & .687 & \multirow{2}{*}{.779} & \multirow{2}{*}{.639} & \multirow{2}{*}{.714} \\
\hline I have required skill to participate soccer & .773 & & & \\
\hline I try to develop my soccer skill & .802 & \multirow{3}{*}{.899} & \multirow{3}{*}{.749} & \multirow{3}{*}{.835} \\
\hline I try to acquire advanced knowledge on soccer & .740 & & & \\
\hline I try to achieve my goal on soccer & .830 & & & \\
\hline Soccer gave me an accomplishment & .802 & \multirow{4}{*}{.924} & \multirow{4}{*}{.759} & \multirow{4}{*}{.863} \\
\hline Soccer makes me feel refreshed & .905 & & & \\
\hline I am very satisfied with participating soccer & .870 & & & \\
\hline Soccer helps me to build social relationship & .572 & & & \\
\hline When introducing myself, I always mention about leisure activity & .880 & \multirow{3}{*}{.894} & \multirow{3}{*}{.740} & \multirow{3}{*}{.880} \\
\hline Leisure activity I participate in is my typical characteristic & .750 & & & \\
\hline Soccer and I feel a sense of unity & .900 & & & \\
\hline I feel identity with others who participate in soccer & .795 & .820 & .605 & .768 \\
\hline
\end{tabular}




\begin{tabular}{lll}
\hline I know the unique ethos of others who participate in soccer & .696 \\
I have same goal with others participating in soccer together & .681 & \\
Leisure Facilitators & .705 & .789 .560 \\
I decide on my own to participate in soccer & .813 & .726 \\
I have the confidence to participate in soccer & .867 & .818 \\
I am active in terms of characteristics & .607 \\
I have partners with whom to participate in soccer & .726 & .741 \\
I have a person to guide soccer activity & .556 & .669 \\
I have family members with whom to participate in soccer & .644 & .642 \\
A 5-day work system supports my leisure activities & .660 & .518 \\
There are enough soccer facilities in which to participate in the community & .745 \\
There are soccer facilities around my house & .751 \\
I have enough time to enjoy soccer & \\
My family supports my soccer activity very well & \\
\hline
\end{tabular}

\subsection{Correlation Analysis}

To examine the relationship between the sub-dimensions of leisure facilitators and serious leisure, Pearson's product moment correlation coefficient was calculated. According to the results of the correlation analysis, there was a positive and significant relationship between the sub-dimensions of leisure facilitator and serious leisure. All dimensions of leisure facilitators are significantly positively correlated with serious leisure. Specifically, Intrapersonal facilitators had the highest correlation with serious leisure.

In addition, before multiple regression analysis was conducted, multicollinearity must be tested as it is general problem. As Table 4 indicates, the correlation coefficient among variables in this study ranged from .339 to .655. The results of correlation analysis in this study indicate that there were no multicollinearity problems. The results of correlation analysis are as displayed in Table 4.

Table 4. The results of correlation analysis

\begin{tabular}{ccccc}
\hline & 1 & 2 & 3 & 4 \\
\hline 1.Intrapersonal facilitator & 1 & & & \\
2. Interpersonal facilitator & $.348^{* * *}$ & 1 & 1 & \\
3. Structural facilitator & $.339^{* * *}$ & $.348^{* * *}$ & $.366^{* * *}$ & 1 \\
4. Serious leisure & $.655^{* * *}$ & $.382^{* * *}$ & \\
\hline
\end{tabular}

$* p<.05, * * p<.01, * * * p<.001$

\subsection{Relationship between Leisure Facilitator and Serious Leisure}

To examine the relationship between leisure facilitators and serious leisure among female college soccer participants, multiple regression analysis was conducted. The results of the analysis on the effect of leisure facilitators on serious leisure are shown in Table 5. All the sub-factors of leisure facilitator had an effect on serious leisure. The factor that was found to have the most influence on serious leisure among female college soccer participants was the intrapersonal facilitator $(\beta=.535)$, followed by the structural facilitator $(\beta=.156)$ and the interpersonal facilitator $(\beta=.152)$. The value of $R^{2}$ was 0.464 , which means it explains $46.4 \%$ of the total variation. The value of $\mathrm{F}$ was 63.169 , which was statistically significant $(p<.001)$.

Table 5. Results of multiple regression analysis

\begin{tabular}{ccccc}
\hline & B & SE & $\boldsymbol{\beta}$ & $\boldsymbol{t}$ \\
\hline 1. Intrapersonal facilitator & .334 & .034 & .535 & $9.813^{* * *}$ \\
2. Interpersonal facilitator & .097 & .035 & .152 & $2.777^{* *}$ \\
3. Structural facilitator & .091 & .032 & .156 & $2.861^{* *}$ \\
\hline
\end{tabular}

$F=63.169^{* * *}, R^{2}=0.464$

$* p<.05, * * p<.01, * * * p<.001$

\section{Discussions}

This study analyzes the factors of leisure facilitators that affect individual participation in leisure activities. 
Although previous studies on leisure participation have focused on leisure constraints in general, leisure facilitators is also thought to be a significant factor for the participation in leisure activities. Therefore, this study analyzes the relationships between leisure facilitators and serious leisure in order to understand the leisure behaviors of female college students participating in soccer.

We have found that intrapersonal facilitator positively affects serious leisure among their factors of leisure facilitators. Iso-Ahola (1999) observes that individual motives, values, and personalities are critical elements for the promotion of leisure activities, which means that internal motivation and promotion significantly affect leisure activity participation (Song \& Lee, 2006; Yarnal \& Doweler, 2002). Female college students who play soccer also voluntarily select soccer according to their individual preferences and participate in serious leisure. Lawton (1994) suggests that individuals with enthusiasm who deeply engage in leisure activities also engage in serious leisure participation.

We have also found that interpersonal facilitator positively affects serious leisure. Collaborating with and encouragement from friends and sharing successful leisure experiences with acquaintances relates positively to the participation in physical activity for female adolescents (Bungum \& Vincent, 1997). Csikszentmihalyi and Kleiber (1991) state that support from family members or colleagues in the performance of important roles conductes to special experiences in leisure activities. Passmore and French (2001) demonstrate that social interactions are significant for adolescents' leisure activities, and thereby enhancing their engagement.

Soccer as a group activity is naturally linked to serious leisure when the interpersonal facilitator preceded it. Sa et al. (2015) confirm that the interpersonal facilitator of women in running events positively affects the recreation specialization that develops through continual leisure activity participation, which support the findings of this study. This implies that serious leisure activities of individual require interpersonal facilitator from friends and peers (Ditton, Loomis, \& Choi, 1992).

Finally, we have found that structural facilitator positively affects serious leisure. Raymore (2002) defines a structural facilitator as a social system, institution, and value frame that can foster and reinforce the preference for leisure activity participation. The endeavor factor of serious leisure that structural facilitator manifest can be described as a tendency of continuous attempts for achieving the objectives of leisure activities or competence betterment. To strengthen the preference of female college students playing soccer and attracting their continued engagement, structural facilitator should become the foundation of institutions, environments, and social systems (Henderson \& Bialeschki, 2005). In this sense, Treiber, Baranowski, Bradin, Strong, and Knox (1991) state that social support positively influence continual engagement in sports activities.

This study has the three following limitations. First, the leisure facilitators of female students engaged in soccer were measured without the measurement of leisure constraint negotiation strategies. Therefore, follow-up studies should analyze leisure constraint negotiation strategies and leisure facilitators in integrated ways. Second, studies to analyze the relationships between leisure facilitators and serious leisure, targeting female college students who participate in individual activities, including swimming, yoga, running, and fitness, in addition to group activities such as soccer are required because female college students in Korean society more frequently engage in individual sports than group sports such as soccer or baseball. Third, the control variables, such as age, gender, participation level, was not considered. Therefore, following study should include those control variables to complete more accurate result.

Despite its limitations, this study identifies a positive relationship between leisure facilitators and serious leisure among female college students. Although the majority of previous studies barely cover the effects of leisure facilitators for serious leisure, this study suggests the value of leisure facilitators for the participation of female college students.

\section{References}

Bungum, T. J., \& Vincent, M. L. (1996). Determinants of physical activity among female adolescents. American Journal of preventive medicine, 13(2), 115-122.

Calhoun, L. G., \& Tedeschi, R. G. (1999). Facilitating posttraumatic growth: A clinician's guide. Mahwah, NJ: Lawrence Erlbaum.

Chen, K. Y. (2014). The relationship between serious leisure characteristics and subjective well-being of older adult volunteers: The moderating effect of spousal support. Social indicators research, 119(1), 197-210. https://doi.org/10.1007/s11205-013-0496-3

Chun, S., \& Lee, Y. (2008). The experience of posttraumatic growth for people with spinal cord injury. Qualitative Health Research, 18(7), 877-890. https://doi.org/10.1177/1049732308318028 
Crawford, D. W., Jackson, E. L., \& Godbey, G. (1991). A hierarchical model of leisure constraints. Leisure sciences, 13(4), 309-320. https://doi.org/10.1080/01490409109513147

Csikszentmihalyi, M., \& Kleiber, D. A. (1991). Leisure and self-actualization. Benefits of leisure, 91-102.

Dilley, R. E., \& Scraton, S. J. (2010). Women, climbing and serious leisure. Leisure Studies, 29(2), 125-141. https://doi.org/10.1080/02614360903401927

Ditton, R. B., Loomis, D. K., \& Choi, S. (1992). Recreation Specialization: Re-conceptualization from a social world's perspective. Journal of Leisure Research, 24, 33-51.

Fornell, C., \& Larcker, D. F. (1981). Evaluating structural equation models with unobservable variables and measurement error. Journal of marketing research, 39-50. https://doi.org/10.2307/3151312

Hair, J. F., Black, W. C., Babin, B. J., Anderson, R. E., \& Tatham, R. L. (2006). Multivariate data analysis (Vol. 6). Upper Saddle River, NJ: Pearson Prentice Hall.

Henderson, K. A., \& Bialeschki, M. D. (2005). Leisure and active lifestyles: Research reflections. Leisure Sciences, 27, 355-365. https://doi.org/10.1080/01490400500225559

Hubbard, J., \& Mannell, R. C. (2001). Testing competing models of the leisure constraint negotiation process in a corporate employee recreation setting. Leisure Sciences, 23(3), 145-163. https://doi.org/10.1080/014904001316896846

Iso-Ahola, S. E. (1999). Motivational foundations of leisure. Leisure studies: Prospects for the twenty-first century, 35-51.

Jackson, E. L. (1993). Recognizing patterns of leisure constraints: Results from alternative analyses. Journal of leisure research, 25(2), 129.

Jackson, E. L., Crawford, D. W., \& Godbey, G. (1993). Negotiation of leisure constraints. Leisure sciences, 15(1), 1-11. https://doi.org/10.1080/01490409309513182

Jo, E. J. (2010). A study on the Characteristics of the Sub-culture of Female College Soccer Players(Unpublished Master's thesis). Sookmyung Women's University, Seoul, Korea.

Kim, B., Heo, J., Chun, S., \& Lee, Y. (2011). Construction and initial validation of the leisure facilitator scale. Leisure/Loisir, 35(4), 391-405. https://doi.org/10.1080/14927713.2011.648402

Kline, R. B. (2015). Principles and practice of structural equation modeling. Guilford publications.

Korotkov, D., McLean, H., \& Hamilton, L. (2011). Predicting leisure satisfaction: A comparative analysis of the agency and communion model with the five-factor model of personality. The American Association of Behavioral and Social Sciences Journal, 15, 1-20.

Lawton, M. P. (1994). Personality and affective correlates of leisure activity participation by older people. Journal of Leisure Research, 26(2), 138.

Lewis, J., Patterson, I., \& Pegg, S. (2013). The serious leisure career hierarchy of Australian motorcycle road racers. World Leisure Journal, 55(2), 179-192. https://doi.org/10.1080/04419057.2013.782563

Mackellar, J. (2009). An examination of serious participants at the Australian Wintersun festival. Leisure Studies, 28(1), 85-104. https://doi.org/10.1080/02614360802613879

Ministry of Culture, Sports and Tourism (2015). Survey on citizens' sports participation. http://www.index.go.kr/potal/main/EachDtlPageDetail.do?idx_cd=1658. (07/06/2016).

Nunnally, J. C. (1978). C.(1978). Psychometric theory. New York, McGraw-Hill.

Passmore, A., \& French, D. (2001). Development and administration of a measure to assess adolescents' participation in leisure activities. Adolescence, 36(141), 67.

Raymore, L. A. (2002). Facilitators to Leisure. Journal of Leisure Research, 34(1), 37-51.

Sa, H. J., Lee, C. W., Kim, M. J., Chun, S. B., \& Nam, S. B. (2015). Leisure Facilitators and Recreation Specialization for Female Participants in Running Events. Asian Social Science, 11(27), 175. https://doi.org/10.5539/ass.v11n27p175

Song, Y. M., \& Lee, h. (2006). Analysis structural equation model of leisure facilitators: Focused on the five-day classweek system in school. Journal of Tourism and Leisure Research, 18(2), 7-24.

Stanis, S. A. W., Schneider, I. E., Chavez, D. J., \& Shinew, K. J. (2009). Visitor constraints to physical activity in 
park and recreation areas: Differences by race and ethnicity.

Stebbins, R, A. (1982). Serious leisure: A conceptual statement. Pacific Sociological Review, 25(2), 251-272. https://doi.org/10.2307/1388726

Stebbins, R. A. (1992). Amateurs, professionals, and serious leisure. Montreal, Canada: McGill-Queen's University.

Stebbins, R. A. (2001). New directions in the theory and research for serious leisure. Mellen studies in sociology (Vol. 28). Lewinston, NY: Edwin Mellen Press.

Treiber, F. A., Baranowski, T., Braden, D. S., Strong, W. B., Levy, M., \& Knox, W. (1991). Social support for exercise: relationship to physical activity in young adults. Preventive medicine, 20(6), 737-750. https://doi.org/10.1016/0091-7435(91)90068-F

Tabachnick, B. G., Fidell, L. S., \& Osterlind, S. J. (2001). Using multivariate statistics.

Tsaur, S. H., \& Liang, Y. W. (2008). Serious leisure and recreation specialization. Leisure Science, 30(4), 325-341. https://doi.org/10.1080/01490400802165115

Yamal, C. M., \& Dowler, L. (2002). Who is answering the call? Volunteer firefighting as serious leisure. Leisure/Loisir, 27, 161-190. https://doi.org/10.1080/14927713.2002.9651302

\section{Copyrights}

Copyright for this article is retained by the author(s), with first publication rights granted to the journal.

This is an open-access article distributed under the terms and conditions of the Creative Commons Attribution license (http://creativecommons.org/licenses/by/4.0/). 